\title{
Exploring the Relationships between Cultural Content and Viewers' Watching Interest: A Study of Tiktok Videos Produced by Chinese Ethnic Minority Groups
}

\author{
Lifu Li and Kyeong Kang \\ Faculty of Engineering and Information Technology, University of Technology Sydney, Australia \\ Lifu.Li@student.uts.edu.au,Kyeong.Kang@uts.edu.au
}

\begin{abstract}
Keyword: Short Video Content, Ethnic Minority Group, Viewers' Watching Interest, Covariance Analysis, Cultural Protection.

Abstract: $\quad$ This research aims to create a framework for ethnic minority groups (EMG) in building visual and aural short video content on social media platforms (SMPs). As the concept of urbanisation prevails in China, both the younger major group and EMG generations gradually accept the modern culture, which results in some traditional culture are faced with the danger of disappearance. In order to protect and spread EMG culture, this paper focuses on the short video created by EMG video producers on the TikTok platform. Through the classification of EMG videos content on the platform, it analyses what kinds of cultural content are effective in attracting viewers' watching interest. Using 1007 EMG videos as base data, the paper applies the covariance analysis method to present the relationships between cultural short video content and viewers' watching interest. Based on the comparisons among the results of different EMGs, the findings can guide EMG video producers to improve their visual content, contributing to EMG cultural protection and cultural diversity.
\end{abstract}

\section{INTRODUCTION}

According to the definition from Qalati et al. (2021), social media is based on Web 2.0 technology, and users can create and share various information with others through the digital world. With the improvement of social networking technology, more and more online services have been offered to users, such as group chat, public posts, distance learning and social games (Chugh \& Ruhi, 2019; Qalati, Li, Ahmed, Mirani, \& Khan, 2021). In China, the messaging app WeChat and the microblogging app Weibo have become the two most popular social media platforms (SMPs), and they have 430 million monthly active users and one billion monthly active users separately (Ren, 2018). However, the situation of traditional SMPs has begun to change in China while the new mode of short video platform established in 2017. This research focuses on one of the latest popular short video platforms, TikTok (Douyin). Unlike traditional SMPs, this video sharing platform launched by ByteDance has successfully attracted more than 500 million active users in three years (Zhou, 2019). As a social networking app, users can create and upload short videos in less than 15 seconds, and the video content can include daily life, landscape, and cultural show. Until July 2020, TikTok has attracted more than 689 million active users worldwide (Li, Fang, Lou, Li, \& Zhang, 2021). The main reason for the popularity of TikTok is the diversity of short video creation and the uncertainty of video content (Bresnick, 2019). This feature makes TikTok stand out from the SMPs and become the most popular entertainment platform for users (Bresnick, 2019). The variety of video content and a 15 -second time limit are beneficial to spread information quickly, as well as the spread of ethnic minority group (EMG) cultural content in a short period (Li \& Kang, 2020). This is the main reason why this study chooses TikTok as the platform for research rather than traditional Chinese SMPs, like WeChat and Weibo. According to Li and Kang's research (2020), TikTok has a close connection with other traditional SMPs, and the content posted on the TikTok platform can be shared conveniently with other popular SMPs. Through the sharing process, more and more users get 
to know TikTok and might become followers of this platform. Based on its massive user base and attractive functions, TikTok is named as the most popular entertainment-oriented platform in China (Zhou, 2019). Among numerous video content produced on the TikTok platform, some are related to EMGs' culture, such as folk dances from the Uygur group, folk songs from the Mongol group, and handworks from the Miao group. To be specific, in China, in addition to the major group Han, there are 55 EMGs, and most of them have their original language and writing system, which is more complex than Western EMGs (Xiong, Jacob, \& Ye, 2016). According to China's national education policy, all EMG students have the right to accept bilingual education at their local schools, which is beneficial for them to inherit their original language (Xiong et al., 2016). Meanwhile, because of their particular living environment and unique cultural background, EMG residents' habits and customs are different from the Han group. This means that compared with Han group users, EMG users from distinctive cultural backgrounds could have different content preferences and produce unique cultural content while using the short video function. Although the content created by EMGs contains some tangible and intangible cultural heritages, most of online users pay more attention to the mainstream culture instead of the EMG culture. Moreover, a large number of EMGs such as Yi, Tibetan, and Uygur live in China's western areas where hold about $64 \%$ of Chinese territory, and the level of economic development is relatively low ( $\mathrm{Li}$, 2012; Yang, Ding, \& D'Alessandro, 2018). Because of China's first wave of urbanisation developed in eastern areas, from 1978 to 2010, many residents, including EMG residents, have moved from western regions to eastern regions. During this process, more and more younger EMG generations have decided to live in urban areas and accept the mainstream culture. This results that EMG culture would be faced with the risk of disappearing. In light of this, it is much meaningful to utilise the influence of TikTok short video platforms to spread and protect EMG culture. Nevertheless, playing the particular strengths of each group and attracting viewers' attention in a short period is worthwhile for this paper to research.

\section{LITERATURE REVIEW}

\subsection{EMG Short Video Producers}

First of all, most previous studies focus on ordinary users in China, and they divide these online users according to their gender, age, and platforms used (Han \& Kim, 2018; Mao, Stillwell, Kosinski, \& Good, 2017). Although the EMGs population is vast and increasingly more EMG individuals begin to use SMPs, few kinds of research distinguish EMGs from the major Chinese group and focus on their particular cultural content. Meanwhile, some papers divide the short video content based on entertainment, politics, and business these three aspects (Han \& Kim, 2018; Zhang, 2020). Other similar studies utilise the content analysis method and summarise some specific content categories, including gaming, sports, and news (Friedlander, 2017; Zimmer \& Scheibe, 2019). However, there has been no study of the classification of cultural video content produced by EMG users. This paper will pay much attention to the cultural context created and uploaded by EMG short video producers on the TikTok platform.

Table 1: Seven main EMGs (Li, 2012; Ma, 2008).

\begin{tabular}{|c|c|c|c|c|c|}
\hline $\begin{array}{l}\text { Main } \\
\text { group }\end{array}$ & Language & Religion & Marriage & $\begin{array}{c}\text { Living } \\
\text { area }\end{array}$ & Characteristics \\
\hline $\begin{array}{c}\text { Group } 1 \\
\text { (Tibetan } \\
\text { and other } 4 \\
\text { groups) }\end{array}$ & Independent & $\begin{array}{c}\text { Tibetan } \\
\text { Buddhism }\end{array}$ & $\begin{array}{c}\text { Inter-ethnic } \\
\text { marriage }\end{array}$ & $\begin{array}{c}\text { Western } \\
\text { areas }\end{array}$ & $\begin{array}{l}\text { Religion } \\
\text { culture }\end{array}$ \\
\hline $\begin{array}{c}\text { Group } 2 \\
\text { (Hui and } \\
\text { other } 3 \\
\text { groups) }\end{array}$ & Mandarin & Islam & $\begin{array}{c}\text { Inter-ethnic } \\
\text { marriage }\end{array}$ & $\begin{array}{c}\text { Scattering } \\
\text { throughout } \\
\text { country }\end{array}$ & Food culture \\
\hline $\begin{array}{c}\text { Group } 3 \\
\text { (Man, } \\
\text { Hezhe, } \\
\text { Xibo) }\end{array}$ & Mandarin & $\begin{array}{c}\text { No } \\
\text { obvious } \\
\text { religion }\end{array}$ & $\begin{array}{c}\text { Marriage } \\
\text { rate with } \\
\text { Han }\end{array}$ & $\begin{array}{c}\text { Scattering } \\
\text { throughout } \\
\text { the } \\
\text { country } \\
\end{array}$ & $\begin{array}{l}\text { Costume } \\
\text { (chi-pao) }\end{array}$ \\
\hline $\begin{array}{c}\text { Group } 4 \\
\text { (Mongolian } \\
\text { and other } 3 \\
\text { group) }\end{array}$ & Mandarin & $\begin{array}{c}\text { Multiple } \\
\text { religion }\end{array}$ & $\begin{array}{l}\text { Marriage } \\
\text { with Han }\end{array}$ & $\begin{array}{c}\text { North area } \\
\text { (Inner } \\
\text { Mongolia ) }\end{array}$ & $\begin{array}{l}\text { Folk Song, } \\
\text { sports }\end{array}$ \\
\hline $\begin{array}{c}\text { Group } 5 \\
\text { (Chaoxian) }\end{array}$ & Independent & \begin{tabular}{|c|} 
No \\
obvious \\
religion
\end{tabular} & $\begin{array}{c}\text { Low } \\
\text { marriage } \\
\text { rate with } \\
\text { Han }\end{array}$ & $\begin{array}{l}\text { North- } \\
\text { eastern } \\
\text { areas }\end{array}$ & Language \\
\hline $\begin{array}{c}\text { Group } 6 \\
\text { (Uyghur } \\
\text { and other } 6 \\
\text { group) }\end{array}$ & Independent & Islam & $\begin{array}{c}\text { Inter-ethnic } \\
\text { marriage }\end{array}$ & $\begin{array}{l}\text { North- } \\
\text { western } \\
\text { areas }\end{array}$ & $\begin{array}{c}\text { Local } \\
\text { landscape }\end{array}$ \\
\hline $\begin{array}{c}\text { Group } 7 \\
\text { (Miao and } \\
\text { other } 30 \\
\text { groups) }\end{array}$ & Mandarin & $\begin{array}{c}\text { Multiple } \\
\text { religion }\end{array}$ & $\begin{array}{c}\text { High } \\
\text { marriage } \\
\text { rate with } \\
\text { Han }\end{array}$ & $\begin{array}{c}\text { Southwest } \\
\text { areas }\end{array}$ & $\begin{array}{c}\text { Handmade } \\
\text { goods, folk } \\
\text { dance }\end{array}$ \\
\hline
\end{tabular}


Moreover, to comprehensively analyse the video content posted by EMGs, the paper draws on Ma's research (2008) and Li's research (2012) and divides 55 EMGs into seven major groups, improving the efficiency of data collection. As Table 1 shows, the division is based on their language, religion, marriage, living area, and ethnic characteristics $(\mathrm{Li}$, 2012; Ma, 2008). For instance, most Tibetan, Yugu group, Menba group, Luoba group, and Tu group have the same religious belief, Tibetan Buddhism, and most of the residents from group 7 speak Mandarin and accept the marriage to the residents from Han group. Therefore, the analysis of cultural vision content and cultural audition content should be distinguished based on seven different main groups. Because of the large population of EMG residents and the complex classification of EMGs, existing studies tend to choose one or two EMGs as their research targets, such as the handwork research from the Dai group and the language research from the Chaoxian group (Oranratmanee, 2020; Xiong et al., 2016). Due to the different cultural environments, the research results from these particular groups cannot be directly applied to other EMGs. Thus, considering this problem, the paper refers to Ma's research (2008) and divides 55 EMGs into seven main groups based on their languages, customs, religions, and residential environment.

\subsection{EMG Cultural Protection}

Some studies related to EMG cultural protection focus on digital technologies, such as 3D model and VR technology (Wu, Wei, Chunjie, Ping, \& Xinye, 2019; Wu, Ying, Chunjie, Lei, \& Jin, 2017), which needs numerous financial and technical supports and cannot be applied in remote areas. Some researchers pay attention to the method of designing various policies to guide young EMG residents to inherit traditional culture (Li \& Zhang, 2017; Long, He, Yu, \& Chen, 2018), but this kind of cultural protection method needs local governments and residents' longterm participation. Compared with previous cultural protection methods, it is more suitable to utilise the considerable influence of the TikTok short video platform and spread EMG culture through various appealing cultural short videos.

Unlike traditional SMPs, various functions on TikTok, like gift sending system, group chat and online store functions, are beneficial for EMG video producers to present their cultural content and promote an online business (Zhou, 2019). Meanwhile,

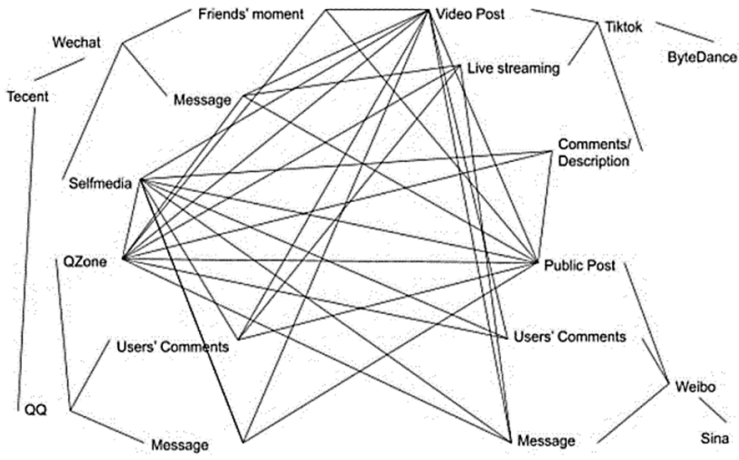

Figure 1: The system map (Li \& Kang, 2020).

TikTok has kinds of connection with other traditional SMPs, which means the content on TikTok can be forwarded conveniently to other popular SMPs (Figure 1). As short video clicks increase, the cultural content of EMG will continue to spread, and the traffic income of EMG producers will increase dramatically. Therefore, this cultural protection method based on the short video platform would not only gives full play to the advantages of EMG culture, but also increases EMGs' income.

\section{RESEARCH GOAL}

With the development of urbanisation and population migration, most of the younger EMG generations have accepted the mainstream culture and neglected their original language and traditional festivals (Zang, 2015). This phenomenon is not conducive to the development of cultural diversity in China. To increase the influence of EMG culture and attract more users' attention, this research analyses what kinds of short video content created by EMG producers can attract users' attention on the TikTok platform. Research results are useful for EMG producers to create more engaging content and enhance their influence in a short period, which could be beneficial to protect EMG culture indirectly.

Specifically, based on the sensory marketing theory, the sensations affecting consumers' attitudes and behaviours include haptics, olfaction, audition, taste, and vision (Krishna, 2012). Due to the limitation of short video communication form, video producers have to pay more attention to the vision part and audition part rather than other sensations. So, through analysing existing short video content uploaded by EMG producers on the TikTok platform, such as costume, folk songs and EMG language, the 
first research aim is as follows: What kinds of EMG video content are related to cultural vision and cultural audition separately?

As mentioned in the literature review part, different EMGs have different characteristics, which means that a detailed classification of EMGs is required in this study. These unique cultural symbols could make a particular group stand out and attract the attention of online viewers on the TikTok platform. Meanwhile, referring to the author Ma's division on EMGs (2008), the research classifies 55 EMGs as seven influential groups. Influenced by the living environment and cultural traditions, these seven major groups' specific cultural preferences might be presented in their short video content. So, the second aim of this paper is as follows: What kinds of short video content are conducive to a particular EMG to attract viewers' watching interest?

\section{RESEARCH FRAMEWORK}

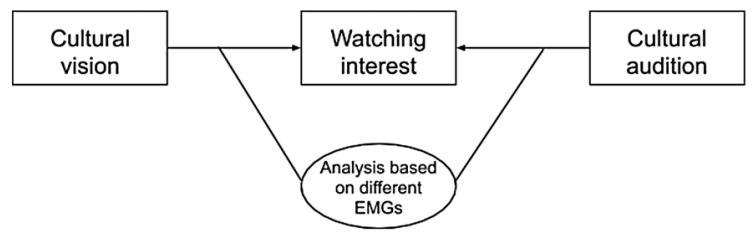

Figure 2: The relationships between cultural sensations and users' watching intention in short video platforms.

As the sensory marketing model created by Krishna (2012), viewers' attitudes to video content can be influenced by haptics, olfaction, audition, taste, and vision. However, on the short video platform, EMG video producers cannot communicate with users face to face, which results in them have to focus on the part of the cultural audition and cultural vision content (Figure 2). Meanwhile, according to the users' continuance intention model based on the uses and gratification research (Li, Liu, Xu, Heikkilä, \& Van Der Heijden, 2015), users' enjoyment of watching videos that can be reflected on the number of likes has a positive impact on their continuance intention or watching interest. In light of this, EMG video producers could provide viewers with hedonic gratification through the cultural audition and cultural vision and attract more viewers' attention in the process.

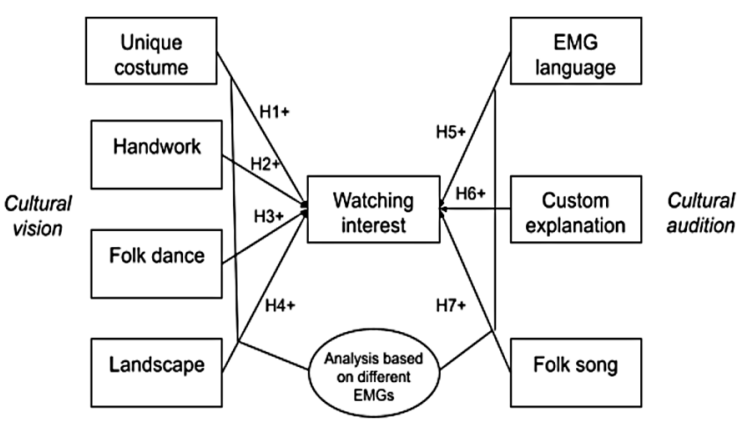

Figure 3: The research framework.

\subsection{Cultural Vision Content}

Based on the sensory marketing model (Krishna, 2012) and the use and gratification research (Li et al., 2015), the research framework established (Figure 3) shows the relationship between cultural sensations created by EMG producers and viewers' watching intention on short video platforms based on various EMGs. Firstly, in addition to the appearance of the characters on the screen, the character's clothing can also give a deep impression to the audience. Specifically, most EMGs have their unique costumes with various styles and beautiful colour ( $\mathrm{Li}, 2012)$, which can be presented in their short videos and provide viewers with an attractive cultural vision. For instance, at major festivals, Miao girls wear their costumes made by Miao silver to reflect their beauty and show their family status (Liu, 2015). So, for some EMGs, they can wear their beautiful costumes while creating short videos, which could make them stand out and attract viewers' watching interest. Thus, the paper proposes that:

Hypothesis 1: Costume in EMG short video has a positive relationship with users' watching intention.

Moreover, some EMGs are good at handworks that belong to the tangible cultural heritage. The EMG residents living in the Xiangxi area have a rich heritage of wood carvings, such as woodcarving grid door and window patterns with a long history (Baishan, 2012). Given its unique cultural significance, wood carving has a considerable influence on the art market. Thus, cultural handworks from EMGs would also have the advantage to attract short video viewers' attention. Thus, the paper proposes that:

Hypothesis 2: Handwork in EMG short video has a positive relationship with users' watching intention. 
Unlike costume and handwork, folk dance belongs to an intangible cultural heritage that is popular in China. For example, influenced by the cultural atmosphere, some Uighur residents have a cheerful personality and are naturally skilful at dancing, although most of them have not accepted professional dance training (Wong, 2018). In recent years, a large number of dances with ethnic characteristics have been recorded in short videos and uploaded to the short video platform. Thus, the paper proposes that:

Hypothesis 3: Folk dance in EMG short video has a positive relationship with users' watching intention.

Most EMG residents' living environment is far from urban pollution, which could provide tourists with some picturesque landscapes and places of interest, such as beautiful autumnal colours in the Kanas area and highland scape in the Jiuzhaigou area (Yang, Ryan, \& Zhang, 2014). All of these attractive landscapes have been applied by some EMG video producers on the short video platform, which could alleviate the visual fatigue of the city dwellers and have a positive impact on viewers' watching interest. So, the landscape visual content produced by EMGs could have a positive relationship with users' watching intention. Thus, the paper proposes that:

Hypothesis 4: Landscape in EMG short video has a positive relationship with users' watching intention.

\subsection{Cultural Audition Content}

Most EMGs have their original language and writing systems. For example, influenced by Korean waves, including Korean TV programs and idol groups, more and more younger Chinese generations are curious about Korean culture and prefer to choose the Korean language as their second language (Ahn, 2014; Jang \& Paik, 2012). Within this environment, many Korean (Chaoxian) group users in China utilise this opportunity and design many language course videos to enhance their influence. So, the paper hypothesises:

Hypothesis 5: EMG language in EMG short video has a positive relationship with users' watching intention.

Most EMGs have their original religion, such as Tibetan Buddhism. In Tibetan culture, OM MANI PADME HUM is usually carved in some stones, placed in prayer wheels, and recited every day by all Tibetans (Campbell, 2018), which provides outsiders with a sharp mental shock. So, these customs like religions, festivals, and etiquettes can be introduced and explained by EMG video producers. Thus, the paper hypothesises:

Hypothesis 6: Custom explanation in EMG short video has a positive relationship with users' watching intention.

In addition to language, some EMGs show the talent for music, such as the famous grassland songs created by Mongolians (Henochowicz, 2008). Unlike popular songs, these folk songs could have unique regional characteristics and reflect their EMGs' history and religious beliefs, which has a unique appeal to the audience (Henochowicz, 2008). Therefore, folk songs produced by EMGs could have a positive relationship with viewers' watching intention. Thus, the paper hypothesises:

Hypothesis 7: Folk song in EMG short video has a positive relationship with users' watching intention.

\section{METHODOLOGY}

\subsection{Research Setting and Measurement}

In this research, we organise nine students and teachers from China as a research team, and they can be not only able to distinguish the EMG language from the Chinese language but also have extensive academic experience in the use of short video platforms, especially TikTok. Table 2 shows the basic information of research team members, and most of them have used TikTok for more than one year. Meanwhile, we require the research team members to read the related literature about EMGs, which is beneficial for them to learn the basic knowledge of EMGs and understand various ethnic characteristics. Due to the situation of COVID-19, the study decides to promote a distance-training for this team through the Zoom platform. After this, the research team promotes online observation based on the content analysis method (Neuendorf \& Kumar, 2015), and categorises the various EMG video content from July 2020 to August 2020 based on the research model.

Moreover, to ensure objectivity in content collection and scoring, the research members are not fixed and focus on one specific EMG, but rotates every three days (Krippendorff, 2018). We also provide the research team with a particular content categorisation and scoring criteria table based on the research model. As Table 3 shows, the research team 
Table 2: The basic information of research team members.

\begin{tabular}{|c|l|c|c|}
\hline ID & Gender & Age & Years of using TikTok \\
\hline 1 & Male & 20 & 2 \\
\hline 2 & Female & 20 & 1 \\
\hline 3 & Female & 49 & 1 \\
\hline 4 & Female & 19 & 1 \\
\hline 5 & Female & 20 & 1.5 \\
\hline 6 & Male & 26 & 2 \\
\hline 7 & Male & 27 & 2 \\
\hline 8 & Female & 26 & 1 \\
\hline 9 & Male & 27 & 2 \\
\hline
\end{tabular}

can refer to the scoring criteria table, which is based on specific examples of EMG short videos on the TikTok platform. Considering the number of questions and the amount of research team members, the paper refers to the Likert 7 point scale (Dawes, 2008) to increase the accuracy of the score. The range is from the lowest score $=2$ to the highest score $=7$, and 1 point means there is no related content in this EMG short video. Before team members scoring, we use some EMG short video examples to help them understand the scoring criteria. Due to the paper format's limitation, the paper only provides the screenshot of an example in Table 3, which could assist readers in understanding.

Table 3: The scoring criteria of EMG short video content.

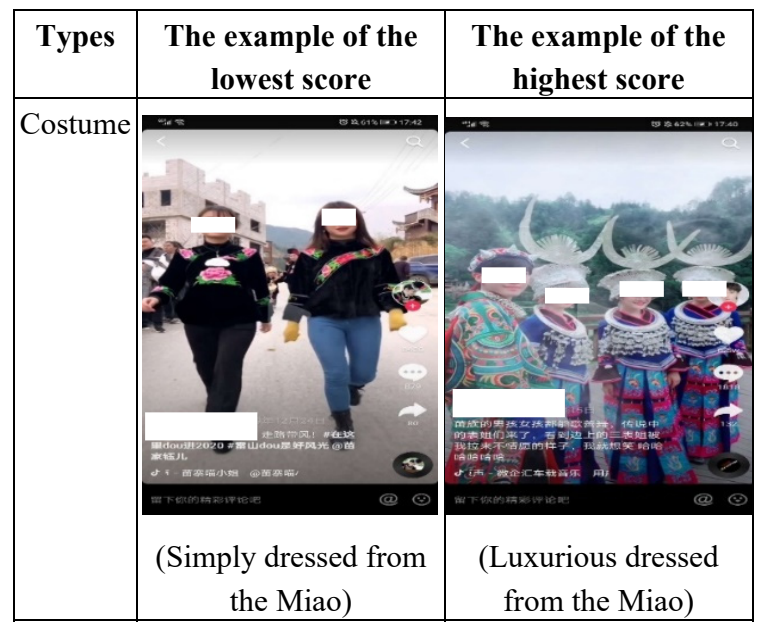

Furthermore, except for the necessary information of the EMG video producers, including producers' gender and group, we ask the research team to record the number of like that is utilised to evaluate short video viewers' watching interest of these EMG short video content. In order to reflect the relevance between cultural content and viewers' watching interest, we divide these different number of likes into seven dimensions, from the lowest 1 to the highest 7 . Meanwhile, because of the length of time having a direct impact on the number of "likes", team members should set the video release time within 24 hours during the statistical process. According to the score uploaded by the research team, the paper utilises the covariance analysis method through the SPSS to analyse the relationship between various EMG short video content and viewers' watching interest.

\subsection{Data Collection}

After defining the content categories of EMG short videos and creating essential scoring criteria, from July 2020 to August 2020, the research group has recorded and scored 1007 EMG short videos from the TikTok platform. Among the content recorded (Table 4 ), more than $43 \%$ of video data is from group 7 , and only $5.96 \%$ of the data record is from group 3 . Meanwhile, according to the gender distribution, except for both female and male or no one shown in the short video, more than $54 \%$ of the characters in short videos are females, and only $25 \%$ of characters are males. Through comparison on gender distribution, the statistical results are similar among these seven groups. This claims that, for all EMGs, females in short videos are more popular than males on the short video platform.

Table 4: EMG short videos distribution ( $\mathrm{n}=1007)$.

\begin{tabular}{|l|l|c|}
\hline Group ID & Number & Relative frequency \\
\hline Group 1 & 136 & $13.51 \%$ \\
\hline Group 2 & 74 & $7.35 \%$ \\
\hline Group 3 & 60 & $5.96 \%$ \\
\hline Group 4 & 87 & $8.64 \%$ \\
\hline Group 5 & 84 & $8.34 \%$ \\
\hline Group 6 & 131 & $13.01 \%$ \\
\hline Group 7 & 435 & $43.20 \%$ \\
\hline
\end{tabular}

Moreover, according to the data collection, most EMG producers prefer to show their local landscape because they live in remote areas where the environment is different from urban areas. Meanwhile, group 3 and group 4 rarely use their original languages because they have a very high marriage rate with the Han group and gradually accept Han culture (Ma, 2008). EMGs widely adopt both customs and folk songs, but few video producers show the content related to handworks and folk 
dances. This might because they have a marked difference in the skilful difficulty.

\subsection{Data Analysis}

To research the relationship between EMG cultural video content and viewers' watching interest, the study requires team members to score the attractiveness of the video content based on the number of likes in each video. To be specific, we sort 1007 EMG short videos by the number of likes and evenly divide all like numbers into seven levels in order of less to more. The number of recorded videos in each level is the same. As the table of rating shows (Table 5), the amount of 0 to 29 likes is equal to the lowest score 1 point, and the amount of 1476 to 121000 likes is equal to the highest score 7 points. Based on the comparison of the number of likes, group 7 is the most popular among short video viewers, but the videos created by group 2 are not attractive to viewers. This might be because most of the inhabitants of group 7 live with the Han group, and have more similar living habits and cultural background with the Han than other groups.

Table 5: The rating of the number of likes.

\begin{tabular}{|c|c|}
\hline Score & Number of "likes" \\
\hline 1 point & $0-29$ \\
\hline 2 points & $30-74$ \\
\hline 3 points & $75-142$ \\
\hline 4 points & $143-257$ \\
\hline 5 points & $258-504$ \\
\hline 6 points & $506-1462$ \\
\hline 7 points & $1476-121000$ \\
\hline
\end{tabular}

This research utilises the covariance analysis method (Figure 4) to analyse the relationships between various EMG content and viewers' watching interest based on these seven groups' cultural content. Following the formula of covariance, the EMG cultural content score is set to $\mathrm{X}$, and the score of the likes is set to Y. After the calculation, the covariance of the relationships has been present in Table 6. For all EMGs, in addition to the EMG language content, others have a positive relationship with viewers' watching interest, from 0.581 to 0.822 . Specifically, as Table 6 shows, the calculation results will change significantly while comparing different groups specifically. For instance, all kinds of content created by group 1 short video producers are beneficial to attract viewers' watching interest, between 0.122 and 1.924. Still, most of the video content uploaded by group 5 negatively correlates with viewers' watching attention, between -2.06 and -0.847 .

$$
\operatorname{Cov}(X, Y)=E\left[\left(X-\mu_{x}\right)\left(Y-\mu_{y}\right)\right]
$$

Figure 4: The covariance analysis formula.

Table 6: The covariance analysis.

\begin{tabular}{|c|c|c|c|c|c|c|c|}
\hline ID & Custome & Handwork & $\begin{array}{c}\text { Folk } \\
\text { dance }\end{array}$ & Landscape & Language & Custom & $\begin{array}{c}\text { Folk } \\
\text { song }\end{array}$ \\
\hline 1 & 0.439 & 1.386 & 1.924 & 0.395 & 0.122 & 0.402 & 0.584 \\
\hline 2 & -0.65 & 0.545 & 0.1 & 0.317 & -3.321 & 2.273 & -0.3 \\
\hline 3 & 0.867 & 1.136 & -0.412 & 0.237 & 0.667 & 2.188 & 0.079 \\
\hline 4 & 0.96 & 1.214 & 1.432 & 0.754 & -0.237 & 0.965 & 0.995 \\
\hline 5 & -0.919 & 1.016 & -2.06 & 0.409 & -0.847 & 0.234 & -1.456 \\
\hline 6 & 0.882 & 2.437 & 1.012 & 0.784 & -1.33 & 1.905 & 0.321 \\
\hline 7 & 0.43 & 0.54 & 0.572 & 0.556 & -0.065 & 0.365 & 0.602 \\
\hline All & 0.687 & 0.822 & 0.666 & 0.625 & -0.281 & 0.679 & 0.581 \\
\hline
\end{tabular}

\subsection{Research Results}

Through the comparison among the covariance analysis of all EMGs and every major group, the chart (Table 7) shows the strengths and weaknesses of each group clearly. Firstly, in the custome part, group 3, group 4, and group 6 have more advantages than other groups. This means online viewers on the short video platform tend to follow the video producers from these three groups who wear and present their unique EMG costumes. Secondly, handwork requires EMG video-makers to acquire specific skills, such as silverware manufacturing from the Miao group, foodmaking from the Korean group, and exceptional hunting skills from the Dulong group. No matter which group it is, skilful handwork has a significant appeal to online viewers. Thirdly, the audience on the TikTok platform has strict requirements for folk dance. In China, most folk dances are combined with the culture of villages. In order to cater to people's new aesthetic, in recent years, many dancers from the Han group continue to innovate and improve folk dance performance (Chou, 2016). This may explain why online viewers are not particularly interested in ordinary folk dances. Nevertheless, group 4 and group 6 still show a significant advantage in dance performance, and their covariances scored are 1.432 and 1.012 , respectively. Fourthly, there is a positive relationship between the landscape display and the 
viewers' watching intention in every EMG. This is because most EMG video producers from China's western areas, and the natural scenery in western regions, such as Xinjiang province and Xizang province, is much more beautiful than eastern areas where most Chinese residents live (Wang \& Chen, 2016).

In addition to cultural vision, cultural audition content designed by EMGs also has a strong relationship with short video viewers' watching interest. Firstly, in China, $91.51 \%$ of residents are from the Han group (The sixth nationwide population census, 2010), which means most online users are familiar with Mandarin and might not be interested in the EMG language. Although the data result of EMG language content could recommend $\mathrm{EMG}$ video producers not to display EMG language in their short video content, this recommendation is unbeneficial for EMG language heritage. Secondly, online viewers have an intense curiosity about EMG customs related to group 2, group 3, and group 6, and the covariances scored are 2.273, 2.188, and 1.905 separately, which are much higher than the covariance of whole EMGs that is 0.679 . However, in consideration of the analysis result of EMG language, the video producers who promote custom explanations are best to use Mandarin rather than their original language. Thirdly, compared with the outcome of folk dance, online viewers on the TikTok platform have a higher acceptance of folk songs, especially the folk songs shared by group 4 . This might be based on the efforts of many Mongolian singers, such as Tenger, whose song named 'Mongolian' earned him numerous honours and fame across the country (Henochowicz, 2008). Therefore, celebrities of each EMG have a potential relationship with the cultural prevalence of that group.

Table 7: The comparison of all EMGs.

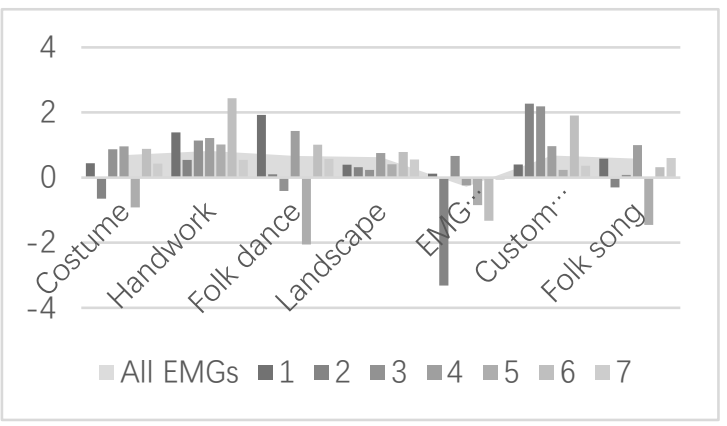

\section{DISCUSSION}

\subsection{Theoretical and Practical Implications}

This study makes several significant theoretical and practical contributions. Firstly, this research establishes the research framework based on the sensory marketing model created by Krishna (2012) and divides EMG cultural content based on cultural vision content and cultural audition content. Although existing studies have proved that viewers' attitudes to regular short video content can be influenced by audition and vision, but it has not analysed whether EMG vision and audition content would affect viewers' watching interest. In order to spread EMG culture on SMPs, this paper promotes the classification of EMG short video content on the TikTok platform. Meanwhile, based on different EMGs' cultural background, it also explores which kind of content effectively attracts viewers' watching interest on short video platforms. Therefore, this study focuses not only on the relationship between specific EMG cultural content and viewers' watching interest, but also on promoting comparisons among seven main EMG cultural content. The research results could be beneficial to provide EMG video producers with some valuable suggestions and guide them to improve their video content. In this process, the EMG culture in China will be spread and inherited.

Moreover, TikTok is an essential platform for EMGs to spread a unique group culture. In recent years, as the concept of urbanisation prevails in China, many younger EMG generations gradually accept the modern culture, which results in some traditional culture facing the danger of disappearance (Xu et al., 2019). Faced with issues, prior studies focus on technical, financial and policy support, which needs numerous financial and human resources. Based on the short video platform's advantages, EMG video producers can improve their cultural video content and attract online viewers' watching interest. With the increase of viewers' watching interest, they are willing to build trust with these EMG video producers and purchase cultural products from them, which helps EMGs spread their unique culture and enhance their income. 


\subsection{Limitations and Future Study}

There are also some drawbacks to this research. Firstly, although the research team members take responsibility for data collection and scoring for each EMG video content, the data results will be subjectively influenced by the research members in the grading process. Secondly, in terms of content classification, the paper divides it into seven categories according to the cultural vision and the cultural audition based on the sensory marketing theory. However, with the deepening of research, the classification of content can be more specific. Finally, the relationships between users and EMG video producers are not limited to the research framework, and there could be other significant relationships that should be focused on, such as the relationship between the number of comments and viewers' watching interest. This kind of research will be promoted on SmartPLS in our future work, and the importance and performance analysis map will be utilised to compare these relationships.

\section{CONCLUSION}

As urbanisation develops in China, many younger EMGs tend to accept the modern culture, which results some traditional EMG culture is faced with the danger of disappearance. In order to protect EMG culture and enhance its influence, this paper focuses on the short video created by EMG users on short video platforms. Based on the research framework and data analysis, this paper discovers what kinds of cultural content are more attractive to online viewers. According to the comparison among the covariance analysis of all major EMGs, the paper provides specific recommendations for each group. For instance, group 4 and group 6 show a significant advantage in dance performance, which means they should display more folk dances in their short videos. With the increase of viewers' watching interest, more and more EMG culture would be protected and accepted.

\section{REFERENCES}

Ahn, J. (2014). The new Korean Wave in China: Chinese users' use of Korean popular culture via the Internet. International Journal of Contents, 10(3), 47-54.
Baishan, L. (2012). Cultural Implication of Woodcarving Grid Door and Window Patterns in Xiangxi Minority Group. Design Research(5), 18.

Bresnick, E. (2019). Intensified Play: Cinematic study of TikTok mobile app. Research Gate, (accessed 5 January 2020).

Campbell, J. (2018). Traveller in space: gender, identity and Tibetan Buddhism: Bloomsbury Publishing.

Chou, E. S. (2016). Folk Dance in China: The Dance Pioneer Dai Ailian, 1916-2006. Paper presented at the Congress on Research in Dance.

Chugh, R., \& Ruhi, U. (2019). Social media for tertiary education. Encyclopedia of education and information technologies. Springer Nature, 10, 978-973.

Dawes, J. (2008). Do data characteristics change according to the number of scale points used? An experiment using 5-point, 7-point and 10-point scales. International journal of market research, 50(1), 61-104.

Friedlander, M. B. (2017). Streamer motives and usergenerated content on social live-streaming services.

Han, M. C., \& Kim, Y. (2018). How Culture and Friends Affect Acceptance of Social Media Commerce and Purchase Intentions: A Comparative Study of Consumers in the U.S. and China. Journal of International Consumer Marketing, 30(5), 326-335.

Henochowicz, A. (2008). Blue Heaven, Parched Land: Mongolian Folksong and the Chinese State. Graduate Journal of Asia-Pacific Studies, 6(1), 37-50.

Jang, G., \& Paik, W. K. (2012). Korean Wave as tool for Korea's new cultural diplomacy. Advances in Applied Sociology, 2(03), 196.

Krippendorff, K. (2018). Content analysis: An introduction to its methodology: Sage publications.

Krishna, A. (2012). An integrative review of sensory marketing: Engaging the senses to affect perception, judgment and behavior. Journal of consumer psychology, 22(3), 332-351.

Li, G., \& Zhang, B. (2017). Identification of landscape character types for trans-regional integration in the Wuling Mountain multi-ethnic area of southwest China. Landscape and Urban Planning, 162, 25-35.

Li, H., Liu, Y., Xu, X., Heikkilä, J., \& Van Der Heijden, H. (2015). Modeling hedonic is continuance through the uses and gratifications theory: An empirical study in online games. Computers in Human Behavior, 48, 261272

Li, L., \& Kang, K. (2020). Analysing Shopping Behavior of the Middle-aged users in Tiktok Live Streaming Platform.

Li, T., Fang, L., Lou, J.-G., Li, Z., \& Zhang, D. (2021). AnaSearch: Extract, Retrieve and Visualise Structured Results from Unstructured Text for Analytical Queries. Paper presented at the Proceedings of the 14th ACM International Conference on Web Search and Data Mining. 
Li, X. (2012). Illustration of 56 ethnic groups in China. Retrieved from http://cnpolitics.org/2012/05/56-ethnicgroups/

Liu, J. (2015). Analysis of" Miao Silver" Market Opportunities. Paper presented at the 2nd International Conference on Civil, Materials and Environmental Sciences.

Long, Y., He, Y., Yu, C., \& Chen, M. (2018). The development status and protection of traditional qiang ethnic minority villages. Paper presented at the AIP Conference Proceedings.

Ma, R. (2008). Types of the Ethnic Relationships in Modern China. Society, 28(1), 1-23.

Mao, M., Stillwell, D., Kosinski, M., \& Good, D. (2017). Testing ageing theory among later middle-aged and older users using social media. Paper presented at the CSCW 2017 - Companion of the 2017 ACM Conference on Computer Supported Cooperative Work and Social Computing.

Neuendorf, K. A., \& Kumar, A. (2015). Content analysis. The international encyclopedia of political communication, 1-10.

Oranratmanee, R. (2020). Cultural geography of vernacular architecture in a cross-cultural context: houses of the Dai ethnic minority in South China. Journal of Cultural Geography, 37(1), 67-87.

Qalati, S. A., Li, W., Ahmed, N., Mirani, M. A., \& Khan, A. (2021). Examining the factors affecting SME performance: the mediating role of social media adoption. Sustainability, 13(1), 75.

Ren, Y. (2018). Know Your Chinese Social Media. Retrieved from https://www.nytimes.com/2018/11/19/ fashion/china-social-media-weibo-wechat.html

The sixth nationwide population census. (2010). Retrieved from http://www.stats.gov.cn/

Wang, L., \& Chen, L. (2016). Spatiotemporal dataset on Chinese population distribution and its driving factors from 1949 to 2013. Scientific data, 3(1), 1-16.

Wong, C.-F. (2018). Uyghur Folk Singing and the Rural Musical Place in Northwest China. In Traditional Musics in the Modern World: Transmission, Evolution, and Challenges (pp. 141-155): Springer.

Wu, X., Wei, G., Chunjie, J., Ping, W., \& Xinye, S. (2019) Application of gesture recognition interaction to digital virtual reconstruction of Yunnan bronze drum. In: Vol. 856. Advances in Intelligent Systems and Computing (pp. 1003-1012).

Wu, X., Ying, S., Chunjie, J., Lei, W., \& Jin, H. (2017). Research on the new way of digital protection and inheritance of the Dai paper-cut. Paper presented at the ICCIA 2017.

Xiong, W., Jacob, W. J., \& Ye, H. (2016). Minority language issues in Chinese higher education: Policy reforms and practice among the Korean and Mongol ethnic groups. Frontiers of Education in China, 11(4), 455-482.

Xu, W., Li, Y., Huo, Y., Tao, J., Guo, W., \& Shao, X. (2019) Digital inheritance of the traditional dulong culture in
Yunnan based on gesture interaction. In: Vol. 856. Advances in Intelligent Systems and Computing (pp. 231-239)

Yang, J., Ryan, C., \& Zhang, L. (2014). External entrepreneurs/investors and guanxi: hostels in a tourism area, Xinjiang, China. International Journal of Contemporary Hospitality Management.

Yang, S., Ding, S., \& D'Alessandro, S. (2018). Are all Chinese shoppers the same? Evidence of differences in values, decision making and shopping motivations between the Han majority and other minorities in China. Journal of Retailing and Consumer Services, 44, 24-34.

Zang, X. (2015). Ethnicity in China: A critical introduction: John Wiley \& Sons.

Zhang, Z. (2020). Infrastructuralization of Tik Tok: transformation, power relationships, and platformization of video entertainment in China. Media, Culture \& Society, 0163443720939452.

Zhou, Q. (2019). Understanding User Behaviors of Creative Practice on Short Video Sharing Platforms $-A$ Case Study of TikTok and Bilibili. University of Cincinnati,

Zimmer, F., \& Scheibe, K. (2019). What drives streamers? Users' characteristics and motivations on social live streaming services. Paper presented at the Proceedings of the 52nd Hawaii International Conference on System Sciences. 